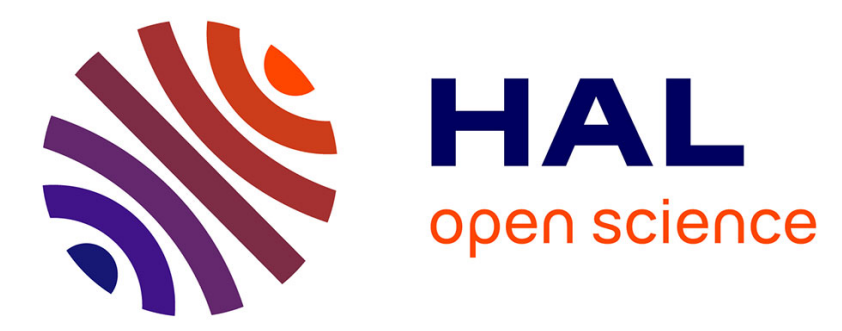

\title{
Controlled Growth of Porphyrin Wires at a Solid-Liquid Interface
}

Christophe Kahlfuss, Yoshihiro Kikkawa, Jennifer A. Wytko, Jean Weiss

\section{To cite this version:}

Christophe Kahlfuss, Yoshihiro Kikkawa, Jennifer A. Wytko, Jean Weiss. Controlled Growth of Porphyrin Wires at a Solid-Liquid Interface. Helvetica Chimica Acta, 2019, 102 (5), pp.e1900058. 10.1002/hlca.201900058 . hal-03015589

\section{HAL Id: hal-03015589 \\ https://hal.science/hal-03015589}

Submitted on 19 Nov 2020

HAL is a multi-disciplinary open access archive for the deposit and dissemination of scientific research documents, whether they are published or not. The documents may come from teaching and research institutions in France or abroad, or from public or private research centers.
L'archive ouverte pluridisciplinaire $\mathbf{H A L}$, est destinée au dépôt et à la diffusion de documents scientifiques de niveau recherche, publiés ou non, émanant des établissements d'enseignement et de recherche français ou étrangers, des laboratoires publics ou privés. 


\title{
Controlled growth of porphyrin wires at a solid-liquid interface
}

\author{
Christophe Kahlfuss, ${ }^{a}$ Yoshihiro Kikkawa, ${ }^{\text {b Jennifer A. Wytko*a and Jean Weiss*a }}$ \\ a Institut de Chimie de Strasbourg, UMR 7177 Université de Strasbourg-CNRS, Institut Le Bel, 4 rue Blaise Pascal, 67008 Strasbourg France, \\ (jwytko@unistra.fr)

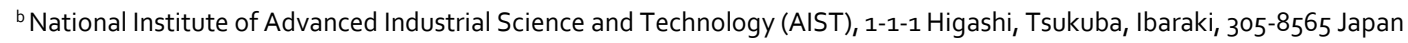

Dedicated to François Diederich on the occasion of his retirement.

\begin{abstract}
Bis(zinc porphyrin) scaffolds bearing $C_{8}$ or $C_{1} 8$ alkyl chains and imidazole end groups self-assembled in a head-to-tail fashion into multiporphyrin assemblies on both HOPG and mica. Due to weaker molecule surface-interactions, longer arrays formed on mica than on HOPG. In both cases, it was essential first to generate monomers that were drop casted on the surface, then to allow time for the bis(zinc porphyrins) to assemble. Although thicker fibrous assemblies were observed with the C8 alkyl substituents than with the longer chains, noncovalent assemblies up to $1 \mu \mathrm{m}$ long were observed for each molecule. These investigations provide a reproducible, noncovalent method to grow porphyrin arrays that may be of interest in molecular electronics for charge transport.
\end{abstract}

Keywords: porphyrinoids $\bullet$ self-assembly $\bullet$ atomic force microscopy $\bullet$ molecular wire

\section{Introduction}

Porphyrins are promising candidates for nanometer-size components in molecular electronics and optoelectronics. These aromatic macrocycles play an important role in photosynthetic processes, ${ }^{[1]}$ hence, the architectures of photosynthetic light harvesting and converting systems have inspired chemists in the design of well-defined single or multi-porphyrinic scaffoldings with tailor-made functions. In-depth studies and rationalization of structure-properties relationships have been possible on single molecule devices to establish the intrinsic properties of the $18 \pi$ electron system and the tuning of the HOMO-LUMO gap by central metal coordination. ${ }^{[2]}$ In an evolution towards multi-porphyrin components, electronic communication and charge transport have been investigated in oligomeric wires ${ }^{[3]}$ of covalently linked ${ }^{[4-8]}$ or fused porphyrin units. ${ }^{[9-14]}$ As a promising result, a very low attenuation factor was measured using break-junction techniques, ${ }^{[15]}$ which reinforced the interest of using porphyrins as tunable junction material. ${ }^{[16-18]}$ More recently, for a series of fused porphyrin oligomers, a substantial increase of conduction was correlated with increasing molecular length at increasing voltages. ${ }^{[19]}$ Multi-porphyrin wires are thus of interest, but their preparation is known to be limited in quantities, even using iterative methods such as oxidative coupling. ${ }^{[9,12]}$ As a result, other conductance measurements on covalent, multi-porphyrin wires are still scarce and primarily concern covalent scaffolds. ${ }^{[20-22]}$

As an alternative to covalently-linked porphyrin wires, non-covalent assembly allows the formation of wires from porphyrin momoners that are relative simple to prepare. Due to the reversibility of axial ligand binding on metalloporphyrins and the possible self-correction of errors, metal coordination quickly appeared to be a powerful tool to control the formation of multi-porphyrin scaffolds. ${ }^{[23,24]}$ The axial binding of imidazoles to metal porphyrins has served as the driving force for self- assembly of relatively linear structures. ${ }^{[25-32]}$ As a first step towards conducting, self-assembled porphyrin wires, the group of Kobuke grew porphyrin chains perpendicular to a gold electrode by self-assembled monolayer techniques ${ }^{[33]}$ and later connected gold nanoparticles by coordination-linked chains. ${ }^{[34]}$ However, rationalization of the structureproperties relationship remains to be established due to the lack of reproducibility and the difficulties in controlling the morphology of the nano-objects formed.

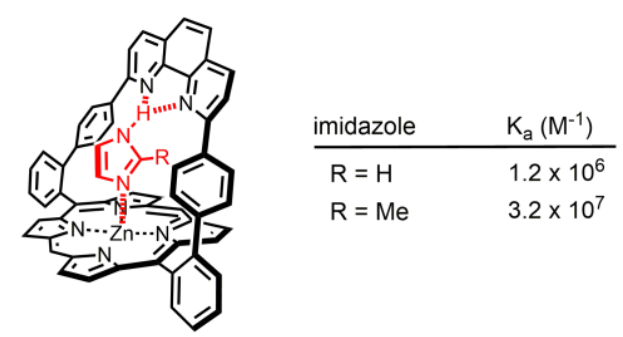

Figure 1. Selective imidazole binding within a phenanthroline-strapped porphyrin in $\mathrm{CH}_{2} \mathrm{Cl}_{2}$ at $298 \mathrm{~K}$. Association constants taken from reference 36 .

Our noncovalent porphyrin arrays take advantage of the selective binding of imidazole within the cavity of a phenanthroline-strapped zinc

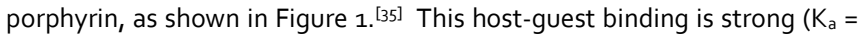
$10^{6}-10^{7} \mathrm{M}^{-1}$ ) in chlorinated solvents due to a combination of three noncovalent interactions: metal-ligand coordination, hydrogen bonding of the imidazole's $\mathrm{NH}$ to the phenanthroline's nitrogen atoms, and pi-pi stacking of the imidazole and the phenyl spacers of the strap. ${ }^{\left[{ }^{36]}\right.}$ The hydrogen bond contributes significantly to this high association constant that is two to three orders of magnitude higher than for $N$ methylimidazole, which cannot form a hydrogen bond with the phenanthroline and thus binds at the open face of the zinc porphyrin. By functionalizing the strapped porphyrin with one imidazole arm, the selective imidazole binding within the phenanthroline strap of a second 
molecule led to noncovalent head-to-tail dimers with stability constants on the order of $10^{9} \mathrm{M}^{-1}$ in $\mathrm{CH}_{2} \mathrm{Cl}_{2 .}{ }^{[25]}$ Inspired by Kobuke's work, ${ }^{\left[{ }^{0}-34\right]}$ a bis(zinc porphyrin) Znı (Figure 2) was designed such that head-to-tail binding would lead to an on-going assembly process and generate linear arrays. ${ }^{[26]}$ In an extension of this approach, we report hereafter a general method leading to porphyrin assemblies in a very reproducible way, and most importantly, which exhibits only a very weak surface dependence. The molecular structures produced by this approach could be useful for the systematic studies of conductivity in self-assembled multi-porphyrin materials.

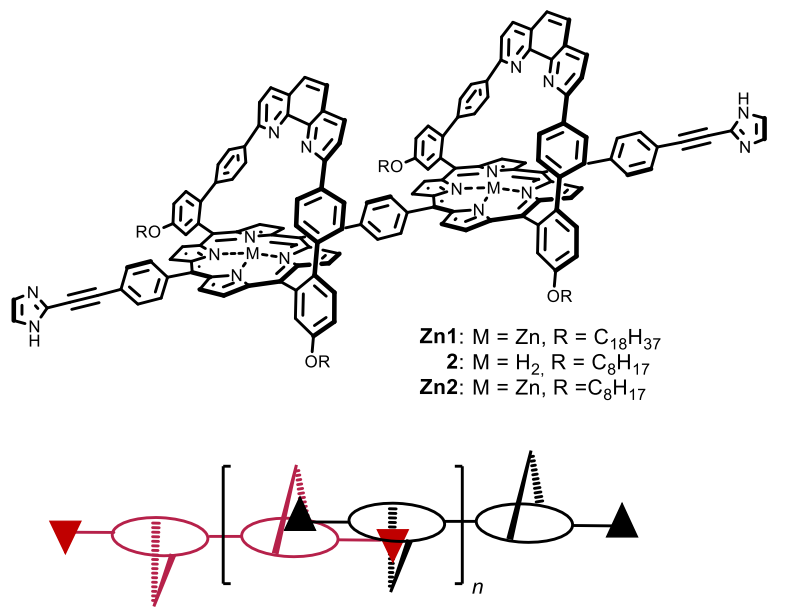

Figure 2. top: Bis(zinc porphyrins) and bottom: schematic representation of their head-to-tail assembly into linear arrays.

\section{Results and Discussion}

The bis(zinc porphyrin) Znz was prepared according to a previously reported strategy ${ }^{[26]}$ for the synthesis of $\mathbf{Z n \mathbf { 1 }}$, starting from the phenanthroline-strapped porphyrin $\mathbf{Z n}^{[28]}$ (Scheme 1). Bromination of this porphyrin with $\mathrm{N}$-bromosuccinimide at $0{ }^{\circ} \mathrm{C}$, followed by treatment with trifluoroacetic acid to demetallate the porphyrin afforded the mesobromo derivative 4 in $67 \%$ yield. The presence of the zinc in the porphyrin core was necessary for regioselective bromination at the meso positions. The zinc was then removed to improve the solubility and facilitate purification of $\mathbf{4}$. Suzuki coupling of two equivalents of $\mathbf{4}$ with benzene1,4-diboronic acid and subsequent deprotection of the imidazoles using TBAF gave the bis-porphyrin 2 as its free base porphyrin derivative in $43 \%$ yield. Metalation with an excess of zinc(II) acetate yielded the desired bis(zinc porphyrin) Znz that precipitated as a green solid. Compound Znz was insoluble in most solvents, but could be dissolved at low concentrations in a coordinating solvent such as pyridine. Mass spectrometry of $\mathbf{Z n} \mathbf{2}$ showed no unmetallated porphyrin species. The ${ }^{1} \mathrm{H}$ NMR spectrum in pyridine provided little information about the structure of the assembled porphyrins (see ESI). However a broad peak observed at 14.1 ppm for the imidazole $\mathrm{NH}$ proton was typical of a hydrogen bond between this proton and the nitrogen atoms of the phenanthroline, ${ }^{[36]}$ indicating some self-assembly even in pyridine as a solvent.
The assembly process of both bis(zinc porphyrins) Zn1 and Zn2 on highly oriented pyrolytic graphite (HOPG) and mica were investigated by atomic force microscopy (AFM). When pyridine solutions of Zn1 were diluted to $1 \mu \mathrm{M}$ in $\mathrm{CHCl}_{3}$ and drop casted on HOPG, only featureless islands or occasional wires were observed. Previous studies on the imidazoledeprotected derivative of Zn3 (Scheme 1) showed that for longer, linear objects to form, it was necessary to first generate monomeric species. ${ }^{[27]}$ Previous ${ }^{1} \mathrm{H}$ and DOSY NMR studies showed that monomer formation could be achieved by heating the compound in pyridine at $80{ }^{\circ} \mathrm{C}$ for 8 days. $^{[27]}$ For all studies described hereafter, this step was thus systematically carried out before diluting the sample in another solvent for deposition. Nevertheless, even after following this procedure, only islandlike aggregates were observed after drop casting to $1 \mu \mathrm{M} \mathrm{CHCl}$ solutions of $\mathrm{Zn1}$ or $\mathrm{Zn2}$ on HOPG, as shown in Figures 3a-b. By allowing 1 day for the assembly to occur at the liquid-surface interface in a solvent-saturated atmosphere, some linear assemblies were seen for Zn1 (Figure 3c), whereas compound Zn2 only aggregated at step edges (Figure $3 \mathrm{~d}$ ). The average length of these assemblies was $230 \pm 100 \mathrm{~nm}(\mathrm{Zn1})$ and $80 \pm 60$ $\mathrm{nm}(\mathbf{Z n 2})$, respectively.

Michelsen and Hunter previously showed that the length of selfassembled porphyrins was concentration dependent in solution. ${ }^{[37]}$ However, in our case at the liquid-solid interface, increasing the concentration of the porphyrin solution to $10 \mu \mathrm{M}$ and allowing it to evolve for a longer period of time ( 5 days rather than 1 day) did not increase the length of wires formed from Zn1 on HOPG (Figure 3e). In addition, fewer wires were observed. For Znz, a few wires formed 5 days after drop casting the more concentrated solution, however these wires were scarce and surrounded by small, featureless islands.

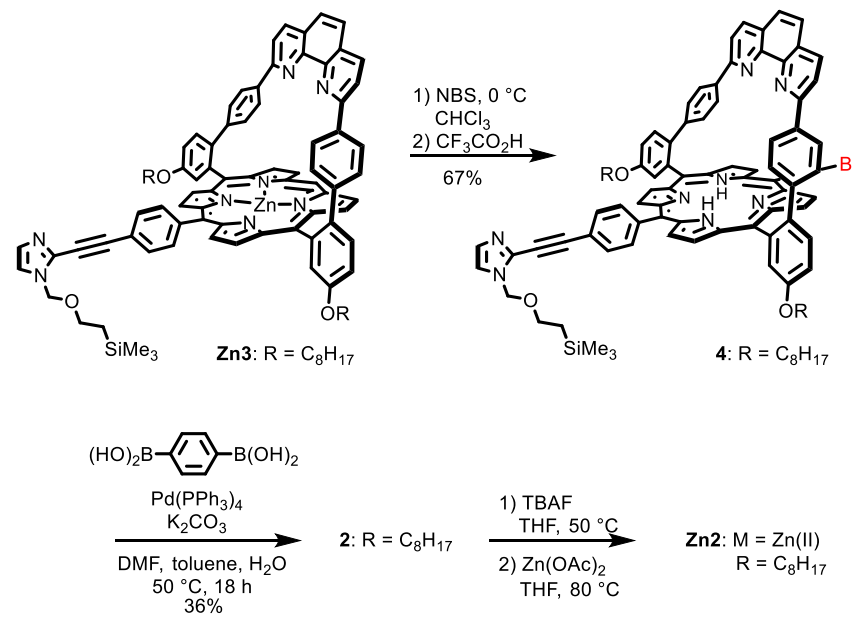

Scheme 1. Synthesis of the bis-porphyrin $Z_{n 2}$ bearing $C_{8}$-chains. 

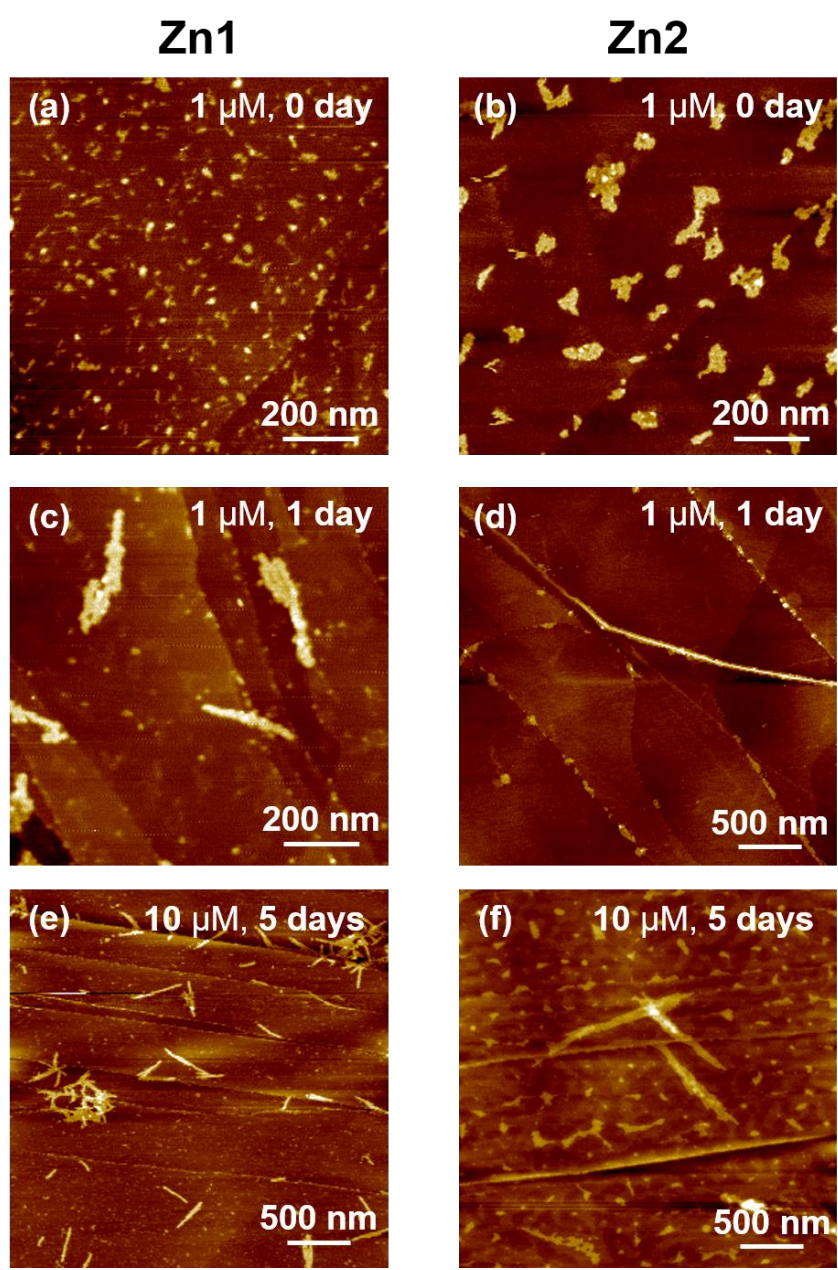

Figure 3. AFM images of Zn1 (left column) and Zn2 (right column) on HOPG, deposited from solutions that were annealed in pyridine for 8 days at $80{ }^{\circ} \mathrm{C}$, then diluted to $1 \mu \mathrm{M}$ (a-d) or $10 \mu \mathrm{M}$ (e-f) in $\mathrm{CHCl}_{3}$ and drop cast on HOPG. Images were taken immediately after deposition (a-b), or after allowing the sample to evolve in a solvent-saturated atmosphere for 1 day (c-d) or 5 days (e-f).

The influence of the solvent used for deposition was also investigated, using THF instead of chloroform. However small aggregates rather than linear assemblies were observed for both compounds drop cast on HOPG (Figure $\mathrm{S}_{1}$ in ESI). The growth of rods was independent of the solvent and concentration, suggesting that the graphite surface was not optimal for growth of long linear assemblies. The growth of such arrays requires the mobility of monomers and short segments on the surface. On HOPG, the surface-molecule interactions, namely van der Waals interactions and $\mathrm{CH}-\pi$ interactions between the alkyl chains and the graphite surface as well as the hydrophobic stacking interactions of HOPG with the porphyrin ring, appear to be sufficiently strong to trap rapidly the building blocks on the surface. Consequently, only short rods form. This observation is in no contradiction with the description of the growth of supramolecular polymers in solution by Hunter. [37] In our case, on HOPG, the assembly process and the equilibria involved are not governed by the classical thermodynamics in solution due to the molecule-surface interaction and the trapping of species on the surface. Alkyl chains and HOPG interact strongly because the C-C bond length $(0.251 \mathrm{~nm})$ and HOPG lattice constant $(0.246 \mathrm{~nm})$ are quite similar, ${ }^{[38]}$ resulting in epitaxial growth, i.e. alkyl chains favor orientation along the HOPG lattice direction with three-fold symmetry. ${ }^{[39,40]}$ This result means the alkyl chains are preferably trapped on the HOPG surface.

These observations and the relatively limited length of the assemblies of both compounds on HOPG prompted us to use a more hydrophilic surface, such as mica, that should result in weaker surfacemolecule interactions than on HOPG and alkyl chain units of Zn1 and Znz. For solutions of $\mathrm{Zn} 1$ diluted to $1 \mu \mathrm{M}$ in $\mathrm{CHCl}_{3}$ or in THF drop cast onto mica, no linear structures were observed, even after 1 day in a solvent-saturated atmosphere (Figure $S_{2}$ in ESI). For Znz, THF (1 $\left.\mu \mathrm{M}\right)$ was not the solvent of choice because the compound was only visible at step edges of the surface, with nothing on plateau areas (Figure $\mathrm{S}_{3}$ in ESI). More promising images were observed for $\mathbf{Z n} \mathbf{2}$ in $\mathrm{CHCl}_{3}(1 \mu \mathrm{M})$. Immediately after drop casting, either rod-like structures or amorphous islands were observed, depending on the sample (Figure $\mathrm{S}_{4 a} \mathrm{a}-\mathrm{c}$ in ESI). In the former case, the $1.8 \mathrm{~nm}$ height of the rods was consistent with the estimated height of $1.6-1.8 \mathrm{~nm}$ for strapped porphyrin, which is either laying on its side (porphyrin perpendicular to the surface) or has an alternating up-down orientation of the two porphyrin rings of Zn2. ${ }^{[26]}$ After 1 day (Figure S4d-f in ESI), rods $150 \pm 50 \mu \mathrm{m}$ long had formed, however the density of assemblies varied depending on the location of the AFM observation. Consequently, the concentration was increased 10-fold, in hopes of growing longer assemblies.

By employing $10 \mu \mathrm{M}$ chloroform solutions of either Zn1 or Znz, more encouraging images were obtained. Consistent with the results obtained at lower concentration, only featureless morphologies were observed immediately after drop casting a solution of Zn1 or Zn2 on mica, (Figures $4 \mathrm{a}$ and $5 \mathrm{a}$ ). This observation confirmed that assemblies were not present in the stock solution at either concentration. However, when the solution of either compound was deposited on the surface then allowed to evolve in a solvent-saturated atmosphere, porphyrin arrays of increasing length grew over $1-8$ days (Figure $4 b$-e and Figure $5 b-d$ ). During this process, substantial amounts of unassembled Zn1 were visible after 1 and 4 days (Figure $4 \mathrm{~b}$ and $4 \mathrm{c}$ ), but they were hardly observed after 8 days, in the $3 \times 3 \mu \mathrm{m}$ image of Figure $4 \mathrm{~d}$. Although unassembled Zn1 remaining around the rods could be still found in the enlarged AFM image (Figure 4e), it is obvious that their amount is largely reduced. The measured height of the unassembled molecules seen as small dots in Figure 4e was ca. 1.0-1.8 $\mathrm{nm}$, which was slightly lower than that of rods. The amorphous nature of the unassembled molecules might allow the lower projection in height than for the rods, possibly due to the pressure induced by the tapping motion of AFM tip. The height of unassembled molecules in Figure $4 \mathrm{~b}$ and $4 \mathrm{c}$ could not be measured because the substrate was already covered with many molecules, making it difficult to define the basal plane. After 8 days under these conditions, although fewer rods were present than on day 1 , the rods of $1 \mathrm{Zn}$ were on average $360 \pm 240 \mathrm{~nm}$ long, with the longest reaching over $1 \mu \mathrm{m}$. The height of the rods was ca. $1.8 \mathrm{~nm}$ (Figure $4 \mathrm{f}$ ), and 
the width was approximately $10-15 \mathrm{~nm},{ }^{1}$ indicating that the structures were composed of a few porphyrin assemblies that were associated in the lateral direction. This entire process was reproducible for both compounds.
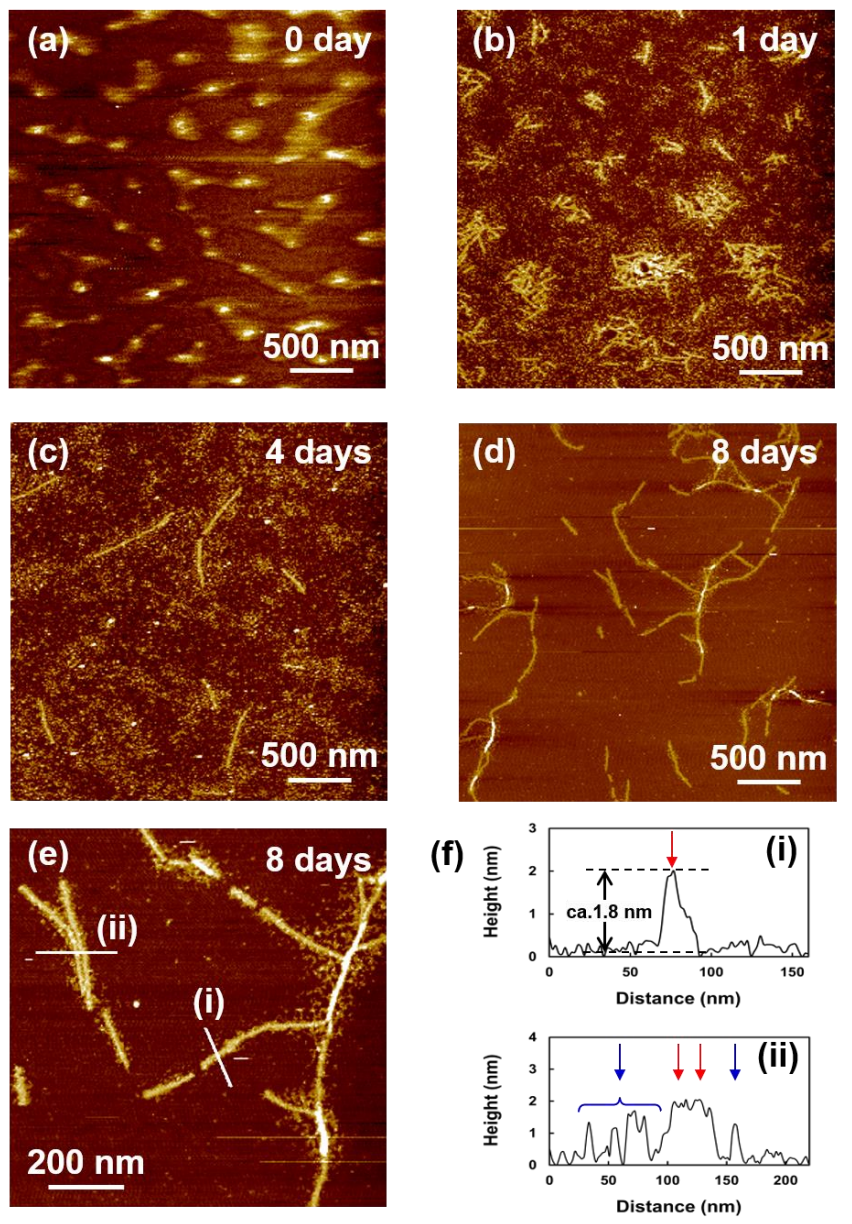

Figure 4. AFM images of $\mathrm{Zn} 1$ on mica. Compounds were annealed in pyridine at $80^{\circ} \mathrm{C}$ for 8 days, diluted to $10 \mu \mathrm{M}$ in $\mathrm{CHCl}_{3}$ and then drop cast on the surface (a) and annealed in $\mathrm{CHCl}_{3}$ for 1 day (b), 4 days (c) and 8 days (d-e). ( $f$ ) Height profiles across the white lines in image (e). The objects indicated by red and blue arrows correspond to assembled rods and unassembled objects, respectively.
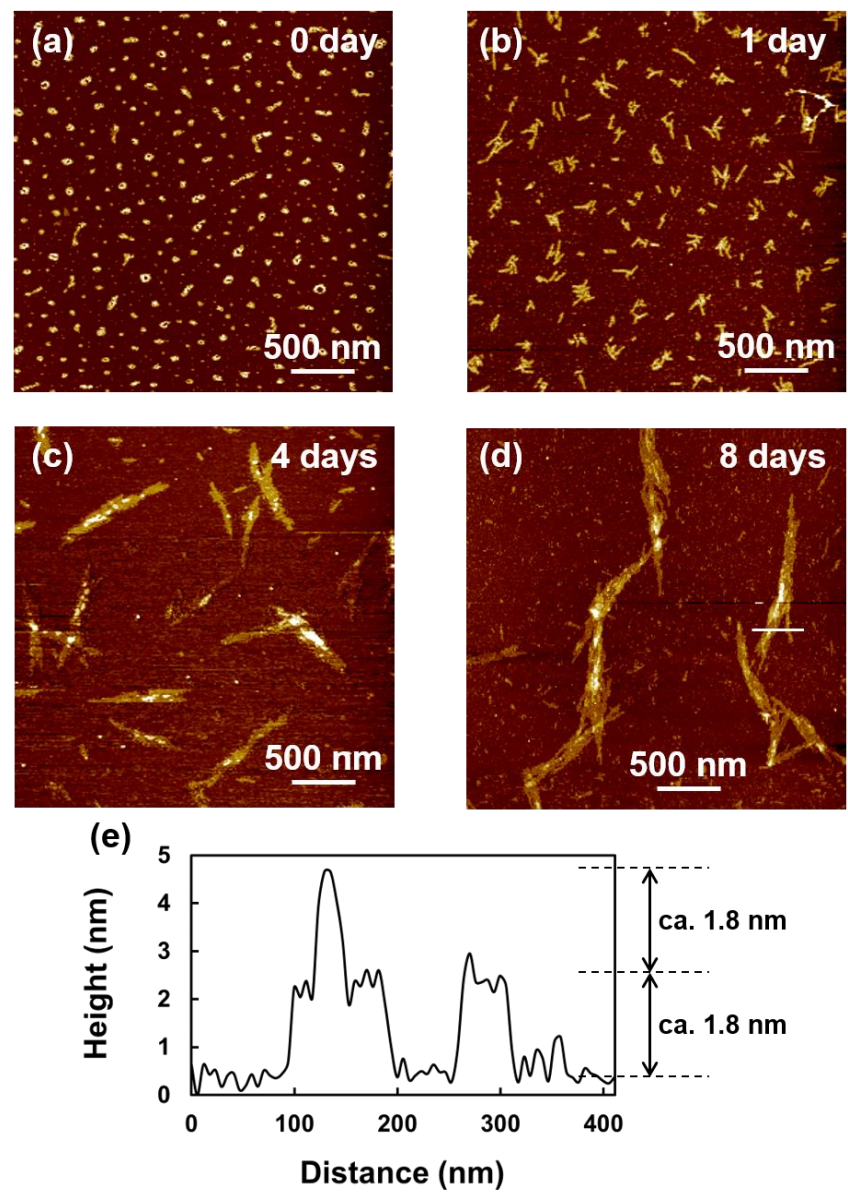

Figure 5. AFM images of $\mathbf{Z n z}$ on mica. Compounds were heated in pyridine at $80^{\circ} \mathrm{C}$ for 8 days, diluted to $10 \mu \mathrm{M}$ in $\mathrm{CHCl}_{3}$ and then drop cast on the surface (a) and stored in a $\mathrm{CHCl}_{3}$-saturated atmosphere for 1 day (b), 4 days (c) and 8 days (d). (f) Height profile of the white line in image (d).

Contrary to the long, thin assemblies of $\mathbf{Z n 1}$, the presence of shorter alkyl chains of Znz led to the growth of larger fibrous structures. The amorphous like islands were observed immediately after deposition of a $\mathrm{CHCl}_{3}$ solution (Figure 5a), and solvent annealing resulted in the growth of the assemblies. Fibrous structures with ca. $1.8 \mathrm{~nm}$ height and $100 \pm 30$ $\mathrm{nm}$ length were found after solvent annealing for 1 day (Figure $5 \mathrm{~b}$ ). Further solvent annealing allowed the aggregation of rods into larger fibrous structures over $1 \mu \mathrm{m}$ long (Figure $5 \mathrm{c}$ ). Stacking of the fibers was also observed in some places (Figure $5 \mathrm{~d}$ and $5 \mathrm{e}$ ). We postulate that for $\mathbf{Z n 2}$, the surface-molecule interactions of the $C 8$ alkyl chains are weaker than intermolecular van der Waals interactions between the alkyl chains. This preference leads to lateral aggregation of several strands of assembled molecules. Furthermore, the more mobile nature of the shorter C 8 chains compared to the $C_{1} 8$ chains may explain why assemblies of $\mathbf{Z n} \mathbf{2}$ aggregate more readily than assemblies of Znı.

The length of a bis(zinc porphyrin) monomer from one imidazole

${ }^{1}$ The measured width was ca. 20-25 $\mathrm{nm}$ and the height was $1.8 \mathrm{~nm}$. The AFM tip broadening factor $(2 \Delta)$ can be calculated by the following equation: $2 \Delta=2[(\mathrm{~h}(2 \mathrm{R}$ $h)]^{\wedge}(1 / 2)$ Where $R$ is the radius of the tip and $h$ is the height of the assembly. Assuming $R=7-10 \mathrm{~nm}$ ( $7 \mathrm{~nm}$ is the nominal value reported by Olympus), the $2 \Delta$ was calculated to be $9.4-11.4 \mathrm{~nm}$, resulting in an actual width of the assembly of ca. 10-15 $\mathrm{nm}$. end to the other was estimated to be $4 \mathrm{~nm}$ based on X-ray of simpler structures. ${ }^{[41]}$ Taking into account the overlap of repeating units upon binding of the imidazole of one unit within the phenanthroline strap of a second unit, a repeat length of $2.5 \mathrm{~nm}$ was estimated (see ESI). ${ }^{[26]}$ Therefore, a $1 \mu \mathrm{m}$ long fiber should contain approximately 400 repeating 
units, or a total of 800 porphyrins. This degree of polymerization matches that reported for Ogawa and Kobuke's noncovalent staircase-assembly of porphyrins. ${ }^{[42]}$ Our noncovalent porphyrin arrays do not quite rival Fuhrhop's covalent porphyrin polymer containing 1200 repeating porphyrin-acetylene-thiophene units ${ }^{[43]}$ or Osuka's tapes with 1024 fused porphyrins. ${ }^{[44]}$ Nevertheless, the noncovalent assembly holds promise as a method to grow junctions between electrodes.

\section{Conclusions}

A reproducible method was developed to grow noncovalent porphyrin arrays on the micrometer scale. The growth occurred at the solvent-surface interface and depended on three factors. First, the initial presence of monomeric bis(zinc porphyrins) was a prerequisite for the assembly process to occur at the interface. Second, the length of alkyl chains was inversely related to the average length of the rods formed. Compared to the $C_{1} 8$ chains, the shorter $\mathrm{C} 8$ chains created fewer, and thus overall weaker molecule-surface interactions. The strength of moleculesurface interactions determined how quickly the molecules were trapped on the surface. Thus, strong van der Waals interactions between the alkyl chains and the hexagonal graphite surface immobilized the molecules and stunted growth. Conversely, longer arrays grew on mica, where the molecules were trapped less quickly than on HOPG due to weaker surfacemolecule interactions. The final factor in the growth of long assemblies was time. The monomers first had to grow into oligomers that continued to grow until no monomers were left at the solvent-surface interface. These oligomers could then assemble into longer rods, however this process was slow because oligomers were less mobile than monomers. Our improved understanding of this growth process could lead to incorporation of these assemblies into junctions.

\section{Experimental Section}

\section{AFM studies}

$\mathrm{Zn} 1$ and $\mathrm{Zn} 2$ were dissolved in pyridine to be $1 \mathrm{mM}$ (stock solution). The stock solution was heated at $80^{\circ} \mathrm{C}$ for 8 days. The solution was diluted in $\mathrm{THF}$ or $\mathrm{CHCl}_{3}$ to a concentration of 1 or $10 \mu \mathrm{M}$. The diluted solution was deposited on freshly cleaved mica (Nisshin EM Co., Ltd).or HOPG (ZYB grade, NT-MDT), and allowed to dry. In some cases, the substrates were solvent-annealed in a closed glass box at room temperature for 1-8 days. Then, AFM observations of the substrates were performed by normal tapping mode or peak-force tapping mode (MultiMode 8, NanoScope V, Bruker) at room temperature. Silicon cantilevers (OMCL-AC240TS-W2) with a spring constant of $2 \mathrm{~N} / \mathrm{m}$ and frequency of $70 \mathrm{kHz}$ (nominal value, Olympus) were selected for tapping mode, whereas silicon cantilevers (SCANASYST-AIR) with a spring constant of $0.4 \mathrm{~N} / \mathrm{m}$ and frequency of 70 $\mathrm{kHz}$ (nominal value, Bruker) were used for peak-force tapping mode.

\section{General Synthetic Information}

Commercially available reagents and solvents were used as purchased without purification. Column chromatography was performed with silica gel from Merck (silica gel 6o, 0.04-0.063 nm). Porphyrin Znz was synthesized according to a literature procedure. ${ }^{[28]}{ }^{1} \mathrm{H}$ NMR spectra were recorded on 400 or $500 \mathrm{MHz}$ Bruker instruments, with chemical shifts relative the solvent as an internal reference: $\mathrm{CHCl}_{3}(7.26 \mathrm{ppm})$. UV-visible spectra were recorded on a Cary 5000 double beam spectrometer. Mass spectra were performed by the Service de Spectrométrie de Masse de I'Institut de Chimie, Université de Strasbourg.

Bromo-porphyrin (4). $\mathrm{N}$-Bromosuccinimide (24.1 mg, $136 \mu \mathrm{mol}$ ) was added to a vigorously stirred solution of $\mathrm{Zn}_{3}$ (191 mg, $136 \mu \mathrm{mol}$ ) in chloroform $(60 \mathrm{~mL})$ at $\circ{ }^{\circ} \mathrm{C}$. The solution was stirred at the same temperature for $15 \mathrm{~min}$, the quenched by adding acetone $(5 \mathrm{~mL})$. Solvents were removed under reduced pressure and the crude product was dissolved in dichloromethane ( $40 \mathrm{~mL})$. TFA (1.5 mL) was added and the green solution was stirred at it for $15 \mathrm{~min}$. A saturated aqueous solution of $\mathrm{NaHCO}_{3}$ was added to neutralize the solution. The organic layer was dried over $\mathrm{Na}_{2} \mathrm{SO}_{4}$, filtered, and evaporated under reduced pressure. The crude product was purified by chromatography column $\left(\mathrm{SiO}_{2}, \mathrm{CH}_{2} \mathrm{Cl}_{2}\right)$ to give 4 (130 mg, $91 \mu \mathrm{mol}, 67 \%)$ as a violet solid. UV-Visible $\left(\mathrm{CH}_{2} \mathrm{Cl}_{2}\right): 298$ (78000), 428 (306000), 523 (16000), 560 (9000), 600 (5000), 657 (4000). ${ }^{1} \mathrm{H}$ NMR $\left(500 \mathrm{MHz}, \mathrm{CDCl}_{3}\right): 9.62(\mathrm{~d}, J=4.7 \mathrm{~Hz}, 2 \mathrm{H}), 8.99(\mathrm{~d}, J=4.7 \mathrm{~Hz}, 2 \mathrm{H}), 8.70(\mathrm{~d}, J$ $=4.6 \mathrm{~Hz}, 2 \mathrm{H}), 8.61(\mathrm{~d}, J=4.6 \mathrm{~Hz}, 2 \mathrm{H}), 8.48(\mathrm{~d}, J=6.3 \mathrm{~Hz}, 1 \mathrm{H}), 8.22(\mathrm{~d}, J=2.6$ $\mathrm{Hz}, 2 \mathrm{H}), 7.97(\mathrm{~d}, J=8.6 \mathrm{~Hz}, 2 \mathrm{H}), 7.87-7.8 \mathrm{o}(\mathrm{m}, 3 \mathrm{H}), 7.78(\mathrm{~d}, J=8.6 \mathrm{~Hz}, 2 \mathrm{H})$, $7.54(\mathrm{~d}, J=8.4 \mathrm{~Hz}, 2 \mathrm{H}), 7.51-7.46(\mathrm{~m}, 4 \mathrm{H}), 7.21(\mathrm{~d}, J=1.0 \mathrm{~Hz}, 1 \mathrm{H}), 7.17(\mathrm{~d}, J$ $=1.0 \mathrm{~Hz}, 1 \mathrm{H}), 6.79(\mathrm{~d}, J=8.4 \mathrm{~Hz}, 4 \mathrm{H}), 6.47(\mathrm{~d}, J=8.4 \mathrm{~Hz}, 4 \mathrm{H}), 5.55(\mathrm{~s}, 2 \mathrm{H})$, $4.30-4.24 .(\mathrm{m}, 4 \mathrm{H}), 3.68(\mathrm{t}, J=8.2 \mathrm{~Hz}, 2 \mathrm{H}), 2.00-1.93(\mathrm{~m}, 4 \mathrm{H}), 1.62-1.55$ $(\mathrm{m}, 4 \mathrm{H}), 1.48-1.25(\mathrm{~m}, 16 \mathrm{H}), 1.00(\mathrm{t}, J=8.2 \mathrm{~Hz}, 2 \mathrm{H}), 0.89(\mathrm{t}, J=6.8 \mathrm{~Hz}, 6 \mathrm{H})$, $0.00(\mathrm{~s}, 9 \mathrm{H}),-2.41(\mathrm{br} \mathrm{s}, 2 \mathrm{H})$. HR-MS $(\mathrm{ESI}+) \mathrm{m} / \mathrm{z}$ calculated for $[\mathrm{M}+2 \mathrm{H}]^{2+}$ : 712.2925, found: 712.2940 .

SEM-protected imidazole bis-porphyrin (5). To a thoroughly degassed mixture of $4(252 \mathrm{mg}, 177 \mu \mathrm{mol})$ in DMF (11 mL), toluene $(6 \mathrm{~mL})$ and water $(0.6 \mathrm{~mL})$, were added benzene-1,4-diboronic acid (13.3 mg, $81 \mu \mathrm{mol})$, $\mathrm{K}_{2} \mathrm{CO}_{3}(67 \mathrm{mg}, 0.48 \mathrm{mmol})$, and then $\mathrm{Pd}\left(\mathrm{PPh}_{3}\right)_{4}(5 \mathrm{mg}, 4 \mu \mathrm{mol})$. The mixture was heated at reflux under argon for $18 \mathrm{~h}$. After evaporation of the solvents, the crude product was dissolved in dichloromethane and washed with a saturated aqueous solution of $\mathrm{NH}_{4} \mathrm{Cl}$, dried over $\mathrm{Na}_{2} \mathrm{SO}_{4}$, filtered. Solvent was evaporated under reduced pressure and the solid was purified by column chromatography $\left(\mathrm{SiO}_{2}, \mathrm{CH}_{2} \mathrm{Cl}_{2} / \mathrm{CH}_{3} \mathrm{OH} / \mathrm{Et}_{3} \mathrm{~N}, 99.2: 0.6: 0.2\right)$ in the dark and to yield the SEM-protected imidazole derivative 5 (79 mg, 64 $\mu \mathrm{mol}, 36 \%)$ as a purple solid that was used without further purification for the next step. UV-Visible $\left(\mathrm{CH}_{2} \mathrm{Cl}_{2}\right): 298$ (188000), 435 (705000), 522 (46000), 560 (27000), 596 (15000), 653 (12000). ${ }^{1 \mathrm{H}}$ NMR ( $500 \mathrm{MHz}, \mathrm{CDCl}_{31}$ ): 9.19 (d, J $=4.6 \mathrm{~Hz}, 4 \mathrm{H}), 9.01(\mathrm{~d}, J=4.6 \mathrm{~Hz}, 4 \mathrm{H}), 8.88(\mathrm{~d}, J=4.6 \mathrm{~Hz}, 4 \mathrm{H}), 8.76(\mathrm{~d}, J=$ $4.6 \mathrm{~Hz}, 4 \mathrm{H}), 8.61(\mathrm{br} \mathrm{s}, 2 \mathrm{H}), 8.31(\mathrm{~d}, J=2.5 \mathrm{~Hz}, 4 \mathrm{H}), 8.26$ (br s, 2H), $8.17(\mathrm{br}$ $\mathrm{s}, 2 \mathrm{H}), 7.94(\mathrm{br} \mathrm{s}, 8 \mathrm{H}), 7.86(\mathrm{br} \mathrm{s}, 2 \mathrm{H}), 7.82(\mathrm{~d}, J=8.7 \mathrm{~Hz}, 4 \mathrm{H}), 7.58-7.43(\mathrm{~m}$, $12 \mathrm{H}), 7.23(\mathrm{~d}, J=1 \mathrm{~Hz}, 2 \mathrm{H}), 7.19(\mathrm{~s}, J=1 \mathrm{~Hz}, 2 \mathrm{H}), 6.83(\mathrm{~d}, J=8.4 \mathrm{~Hz}, 8 \mathrm{H})$, $6.56(\mathrm{~d}, J=8.4 \mathrm{~Hz}, 8 \mathrm{H}), 5.59(\mathrm{~s}, 4 \mathrm{H}), 4.30(\mathrm{t}, J=6.3 \mathrm{~Hz}, 8 \mathrm{H}), 3.71(\mathrm{t}, J=8.2$ 
$\mathrm{Hz}, 4 \mathrm{H}), 2.02-1.94(\mathrm{~m}, 8 \mathrm{H}), 1.6-1.2(\mathrm{~m}, 4 \mathrm{OH}), 1.03(\mathrm{t}, J=8.2 \mathrm{~Hz}, 4 \mathrm{H}), 0.89$ $-0.87(\mathrm{~m}, 12 \mathrm{H}), 0.03(\mathrm{~s}, 18 \mathrm{H}),-2.31$ (br s, 4H). HR MS (ESI+) m/z calc. for $[\mathrm{M}+4 \mathrm{H}]^{4+}: 691.3422$, found $: 691.3473$ and $\mathrm{m} / \mathrm{z}$ calc. for $\left[\mathrm{M}^{+3} \mathrm{H}\right]^{3+}: 921.4456$, found: 921.4539 .

Bis-porphyrin (2). To a solution of $5(79 \mathrm{mg}, 29 \mu \mathrm{mol})$ and tetrabutylammonium fluoride ( $1 \mathrm{M}$ solution in $\mathrm{THF}, 170 \mu \mathrm{l}, 170 \mu \mathrm{mol})$ in anhydrous THF was stirred at $50^{\circ} \mathrm{C}$ for $18 \mathrm{~h}$. The solution was the cooled to $\mathrm{rt}$ and water was added. The solvents were evaporated under reduced pressure. The crude product was purified by column chromatography ( $\mathrm{SiO}_{2}, \mathrm{CH}_{2} \mathrm{Cl}_{2} /$ cyclohexane/THF, 9:9:2; protected from light) to yield 2 (31 mg, $12 \mu \mathrm{mol}, 43 \%$ ) as a purple solid. UV-Visible (DMF): 297 (112000), 435 (411000), 522 (28000), 559 (17000), 596 (9000), 653 (9000). ${ }^{1} \mathrm{H}$ NMR (500 $\left.\mathrm{MHz}_{\text {, }}\left(\mathrm{D}_{7}\right) \mathrm{DMF}\right): 13.08$ (br s, 2H), $11.90(\mathrm{~s}, 2 \mathrm{H}), 9.33-9.27$ (br m, 4H), $9.16-$ $9.11 \mathrm{br}(\mathrm{m}, 4 \mathrm{H}), 9.06-8.99(\mathrm{~m}, 4 \mathrm{H}), 8.95-8.90(\mathrm{~m}, 4 \mathrm{H}), 8.81(\mathrm{br} \mathrm{s}, 2 \mathrm{H})$, $8.70(\mathrm{br} \mathrm{s}, 2 \mathrm{H}), 8.51-8.41(\mathrm{~m}, 6 \mathrm{H}), 8.32-8.19(\mathrm{~m}, 6 \mathrm{H}), 8.10(\mathrm{br} \mathrm{s}, 2 \mathrm{H}), 7.95$ - $7.91(\mathrm{~m}, 4 \mathrm{H}), 7.84(\mathrm{br} \mathrm{s}, 2 \mathrm{H}), 7.75(\mathrm{br} \mathrm{s}, 2 \mathrm{H}), 7.73(\mathrm{br} \mathrm{s}, 4 \mathrm{H}), 7.69(\mathrm{~d}, J=7.5$ $\mathrm{Hz}, 2 \mathrm{H}), 7.61(\mathrm{br} \mathrm{s}, 2 \mathrm{H}), 7.45(\mathrm{~s}, 2 \mathrm{H}), 7.20(\mathrm{~s}, 2 \mathrm{H}), 6.86-6.68(\mathrm{~m}, 14 \mathrm{H}), 4.50$ $-4.35(\mathrm{~m}, 8 \mathrm{H}), 2.04-1.92(\mathrm{~m}, 8 \mathrm{H}), 1.66-1.53(\mathrm{~m}, 8 \mathrm{H}), 1.48-1.19(\mathrm{~m}, 32 \mathrm{H})$, $0.92-0.75(b r m, 12 H),-2.38(s, 4 \mathrm{H})$. MS $(E S I+) m / z$ calc. for $\left[M^{+3}\right]^{3+}$ : 834.3988, found: 834.4014

Bis-(zinc porphyrin) (Znz). Zinc(II) acetate dihydrate (54 mg, $240 \mu \mathrm{mol})$ was added to a solution of 2 ( $31 \mathrm{mg}, 12 \mu \mathrm{mol})$ in THF ( $17 \mathrm{~mL}$ ). The mixture was stirred for $3 \mathrm{~h}$ at $50^{\circ} \mathrm{C}$. After cooling, water was added to the mixture and the resulting green precipitate was filtered, washed thoroughly with water and methanol and dried to afford $\mathbf{Z n 2}$ (30 mg, $11 \mu \mathrm{mol}, 92 \%$ ) as a green solid that was insoluble in most solvents. An NMR spectrum in pydirine- $d_{5}$ did not show a set of well-defined peaks. However the absence of a peak for the porphyrin $\mathrm{NH}$ proton between -2 and $-4 \mathrm{ppm}$ indicated that metalation was complete. MALDI TOF MS m/z calc. for [M] $]^{+}: 2627.997$, found: 2627.801 ( 76 ppm difference between calc. and found mass).

\section{Supplementary Material}

Supporting information for this article is available on the WWW under http://dx.doi.org/10.1002/MS-number.

\section{Acknowledgements}

This work was funded by the JST-ANR grant AIIR.1 4.JTIC.OOO2.O 1 (MECANO). We thank Ms. Mayumi Nagasaki for helping with AFM experiments.

\section{Author Contribution Statement}

JW conceived the project. JW, JAW, CK and YK designed the experiments. CK and YK performed the experiments. JAW and JW wrote the manuscript with contributions and review from all authors.

\section{References}

[1] G. D. Scholes, G. R. Fleming, A. Olaya-Castro, R. van Grondelle, 'Lessons from nature about solar light harvesting,' Nat. Chem. 2011, 3, 763-774.
[2] Z.-F. Liu, S. Wei, H. Yoon, O. Adak, I. Ponce, Y. Jiang, W.-D. Jang, L. M. Campos, L. Venkataraman, J. B. Neaton, 'Control of Single-Molecule Junction Conductance of Porphyrins via a Transition-Metal Center,' Nano Lett. 2014, $14,5365-5370$.

[3] For a recent review, see: T. Tanaka, A. Osuka, 'Conjugated porphyrin arrays: synthesis, properties and applications for functional materials,' Chem. Soc. Rev. 2015, 44,943-969.

[4] H. L. Anderson, 'Conjugated porphyrin ladders,' Inorg. Chem. 1994, 33, 972$981 ;$

[5] V. S. Lin, S. G. DiMagno, M. J. Therien, 'Highly conjugated, acetylenyl bridged porphyrins: new models for light-harvesting antenna systems,' Science 1994, 264, 1105-1111.

[6] J. A. Wytko, V. Berl, M. McLaughlin, R. R. Tykwinski, M. Schreiber, F. Diederich, C. Boudon, J.-P. Gisselbrecht, M. Gross, 'Porphryin-[(E)-1,2Diethynylethene] Scaffolding: Synthesis and Optical and Electrochemical Properties of Multinanometer-Sized Porphyrin Arrays,' Helv. Chim. Acta 1998, 81, 1964-1977.

[7] D. Holten, D. F. Bocian, J. S. Lindsey, 'Probing Electronic Communication in Covalently Linked Multiporphyrin Arrays. A Guide to Rational Design of Molecular Photonic devices, ' Acc. Chem. Res. 2002, 35, 57-69.

[8] M. U. Winters, E. Dahlstedt, H. E. Blades, C. J. Wilson $\neq$, M. J. Frampton, H.L. Anderson, B. Albinsson, 'Probing the Efficiency of Electron Transfer through Porphyrin-Based Molecular Wires,' J. Am. Chem. Soc. 2007, 129, 4291-4297.

[9] A. Osuka, H. Shimidzu, 'meso,meso-Linked Porphyrin Arrays,' Angew. Chem. Int. Ed. Engl. 1997, 36, 135-137.

[10] T. Tanaka, A. Osuka, 'Conjugated porphyrin arrays: synthesis, properties, and applications for functional materials, ' Chem. Soc. Rev. 2015, 44, 94969.

[11] R. Paolesse, L. Jaquinod, F. Della Sala, D. J. Nurco, L. Prodi, M. Montalti, C. Di Natale, A. D'Amico, A. Di Carlo, P. Lugli, K. M. Smith, ' $\beta$-Fused Oligoporphyrins: A Novel Approach to a New Type of Extended Aromatic System,' J. Am. Chem. Soc. 2000, 122, 12295-11302.

[11] A. Tsuda, A. Osuka, 'Fully Conjugated Porphyrin Tapes with Electronic Absorption Bands That Reach into Infrared,' Science 2001, 293, 79-82.

[12] D. H. Yoon, S. B. Lee, K.-H. Yoo, J. Kim, J. K. Lim, N. Aratani, A. Tsuda, A. Osuka, D. Kim, 'Electrical Conduction through Linear Porphyrin Arrays', J. Am. Chem. Soc. 2003, 125, 11062-11064.

[13] B. K. Kang, N. Aratani, J. K. Lim, D. Kim, A. Osuka, K.-H. Yoo, 'Length and temperature dependence of electrical conduction through dithiolated porphyrin arrays', Chem. Phys. Lett. 2005, 412, 303-306.

[15] G. Sedghi, K. Sawada, L. J. Esdaile, M. Hoffmann, H. L. Anderson, D. Bethell, W. Haiss, S. J. Higgins, R. J. Nichols, 'Single Molecule Conductance of Porphyrin Wires with Ultralow Attenuation', J. Am. Chem. Soc. 2008, 130, $8582-8583$

[16] M. Kiguchi, T. Takahashi, M. Kanehara, T. Teranishi, K. Murakoshi, 'Effect of End Group Position on the Formation of a Single Porphyrin Molecular Junction,' J. Phys. Chem. C 2009, 113, 9014-9017.

[17] Z. Li, M.Smeu, M.A. Ratner, E. Borguet, 'Effect of Anchoring Groups on Single Molecule Charge Transport through Porphyrins,' J. Phys. Chem. C 2013, 117, 14890-14898.

[18] M. L. Perrin, C. J. O. Verzijl, C. A. Martin, A. J. Shaikh, R. Eelkema, J. H. van Esch, J. M. van Ruitenbeek, J. M. Thijssen, H. S. J. van der Zant, D. Dulić, 'Large tunable image-charge effects in single-molecule junctions,' Nat. Nanotechnol. 2013, 8, 282-287.

[19] E. Leary, B. Limburg, A. Alanazy, S. Sangtarash, I. Grace, K. Swada, L. J. Esdaile, M. Noori, M. T. González, G. Rubio-Bollinger, H. Sadeghi, A. Hodgson, N. Agrait, S. J. Higgins, C. J. Lambert, H. L. Anderson, R. J. Nichols, 
'Bias-Driven Conductance Increase with Length in Porphyrin Tapes', J. Am. Chem. Soc. 2018, 140, 12877-12883.

[20] G. Sedghi, V. M. García-Suárez, L. J. Esdaile, H. L. Anderson, C. J. Lambert, S. Martín, D. Bethell, S. J. Higgins, M. Elliott, N. Bennett, J. E. Macdonald, R. J. Nichols, 'Long-range electron tunneling in oligo-porphyrin molecular wires', Nature Nanotechol. 2011, 6, 517-523.

[21] G. Sedghi, L. J. Esdaile, H. L. Anderson, S. Martin, D. Bethell, S. J. Higgins, R. J. Nichols, 'Comparison of the Conductance of Three Types of Porphyrin-Based Molecular Wires: $\beta$,meso, $\beta$-Fused Tapes, meso-Butadiyne-Linked and Twisted meso-meso Linked Oligomers', Adv. Mater. 2012, 24, 653-657.

[22] Z.Li, T.-H. Park, J. Rawson, M. J. Therien, E. Borguet, 'Quasi-Ohmic Single Molecule Charge Transport through Highly Conjugated meso-to-meso Ethyne-Bridged Porphyrin Wires,' Nano Lett. 2012, 12, 2722-2727.

[23] For a tutorial review see: E. lengo, E. Zangrando, E. Alessio, 'Discrete Supramolecular Assemblies of Porphyrins Mediated by Coordination Compounds', Eur. J. Inorg. Chem. 2003, 2371-2384.

[24] J. A. Wytko, R. Ruppert, C. Jeandon, J. Weiss 'Metal-mediated linear selfassembly of porphyrins', Chem. Comm. 2018, 54, 1550-1558.

[25] M. Koepf, J. A. Wytko, J.-P. Bucher, J. Weiss, 'Surface-Tuned Assembly of Porphyrin Coordination Oligomers', J. Am. Chem. Soc. 2008, 130, 9994-10001;

[26] M. Koepf, J. Conradt, J. Szmytkowski, J. A. Wytko, L. Allouche, H. Kalt, T. S. Balaban, J. Weiss, 'Highly Linear Self-Assembled Porphyrin Wires', Inorg. Chem. 2011, 50, 6073-6082.

[27] V. Rauch, J. A. Wytko, M. Takahashi, Y. Kikkawa, M. Kanesato, J. Weiss, 'Dynamic Assembled of Porphyrin Wires Trapped on a Highly Oriented Pyrolitic Graphite Surface', Org. Lett. 2012, 14, 1998-2001.

[28] V. Rauch, U. Kikkawa, M. Koepf, I. Hijazi, J. A. Wytko, S. Campidelli, A. Goujon, M. Kanesato, J. Weiss, "Trapping Nanostructures on Surfaces through Weak Interactions," Chem. Eur. J. 2015, 21, 13437-13444

[29] Y. Kobuke, M. Hiyaji, 'Supramolecular Organization of Imidazolyl-Porphyrin to a Slipped Cofacial Dimer,' J. Am. Chem. Soc. 1994, 116, 4111-4112.

[30] K. Ogawa, Y. Kobuke, "Formation of a Giant Supramolecular Porphyrin Array by Self - Coordination," Angew. Chem., Int. Ed.2000, 39, 4070-4073.

[31] N. Nagata, S. Kugimiya, E. Fujiwara, Y. Kobuke, 'Staircase-form assembly with 5,15-bis(imidazol-4-yl)porphinatogallium steps,' New J. Chem. 2003, 27, 743-747.

[32] For a review, see: K. Ogawa, Y. Kobuke, 'Construction and photophysical properties of self-assembled linear porphyrin arrays,' J. Photochem. Photobiol. C 2006, 7, 1-16.

[33] A. Nomoto, Y. Kobuke, 'Photocurrent generation system incorporated with antenna function', Chem. Commun. 2002, 1004-1005

[34] A. Satake, M. Fujita, Y. Kurimotoa, Y. Kobuke, 'Single supramolecular porphyrin wires bridging gold nanoparticles', Chem. Commun. 2009, 12311233

[35] J. Froidevaux, P. Ochsenbein, M. Bonin, K. Schenk, P. Maltese, J.-P. Gisselbrecht, J. Weiss, 'Side Selection of the Fifth Coordinate with a Single Strapped Zinc(II) Porphyrin Host: Full Characterization of Two Imidazole Complexes,' J. Am. Chem. Soc. 1997, 119, 12362-12363.

[36] D. Paul, F. Melin, C. Hirtz, J. Wytko, P. Ochsenbein, M. Bonin, K. Schenk, P. Maltese, J. Weiss, "Induced Fit Process in the Selective Distal Binding of Imidazoles in Zinc(II) Porphyrin Receptors," Inorg. Chem. 2003, 42, 3779-3787.

[37] U. Michelsen, C. A. Hunter, 'Self-Assembled Porphyrin Polymers', Angew. Chem. Int. Ed. 2000, 39, 764-767.

[38] K. W. Herwig, B. Matthies, H. Taub, 'Solvent Effects on the Monolayer Structure of Long n-Alkane Molecules Adsorbed on Graphite,' Phys. Rev. Lett. 1995, 75, 3154-3157.
[39] V. V. Prokhorov, D. V. Klinov, A. A. Chinarev, A. B. Tuzikov, I. V. Gorokhova," N. V. Bovin, 'High-Resolution Atomic Force Microscopy Study of Hexaglycylamide Epitaxial Structures on Graphite,' Langmuir 2011, 27, 58795890.

[40] Y. Zhu, W. Chen, T. Wang, H. Wang, Y. Wang, D. Yan, 'Highly Crystalline Films of Organic Small Molecules with Alkyl Chains Fabricated by Weak Epitaxy Growth,' J. Phys. Chem. B 2016, 120, 4310-4318.

[41] P. Ochsenbein, M. Bonin, K. Schenk, J. Froidevaux, J. Wytko, E. Graf, J. Weiss, 'X-ray Structures of a Phenanthroline-Strapped Porphyrin and Its Dihydrated

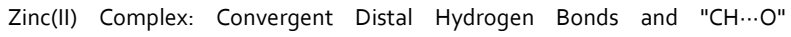
Interactions,' Eur. J. Inorg. Chem. 1999, 1175-1179.

[42] K. Ogawa, Y. Kobuke, 'Formation of a Giant Supramolecular Porphyrin Array by Self-Coordination,' Angew. Chem. Int. Ed. 2000, 39, 4070-4073.

[43] G. Li, T. Wang, A. Schulz, S. Bhosale, M. Lauer, P. Espindola, J. Heinze, J.-H. Fuhrhop, 'Porphyrin-acetylene-thiophene polymer wires,' Chem. Commun. 2004, 552-553.

[44] N. Aratani, A. Takagi, Y. Yanagawa, T. Matsumoto, T. Kawai, Z. S. Yoon, D. Kim, A. Osuka, 'Giant meso-meso-Linked Porphyrin Arrays of Micrometer Molecular Length and Their Fabrication,' Chem. Eur. J. 2005, 11, 3389-3404. 
Entry for the Table of Contents

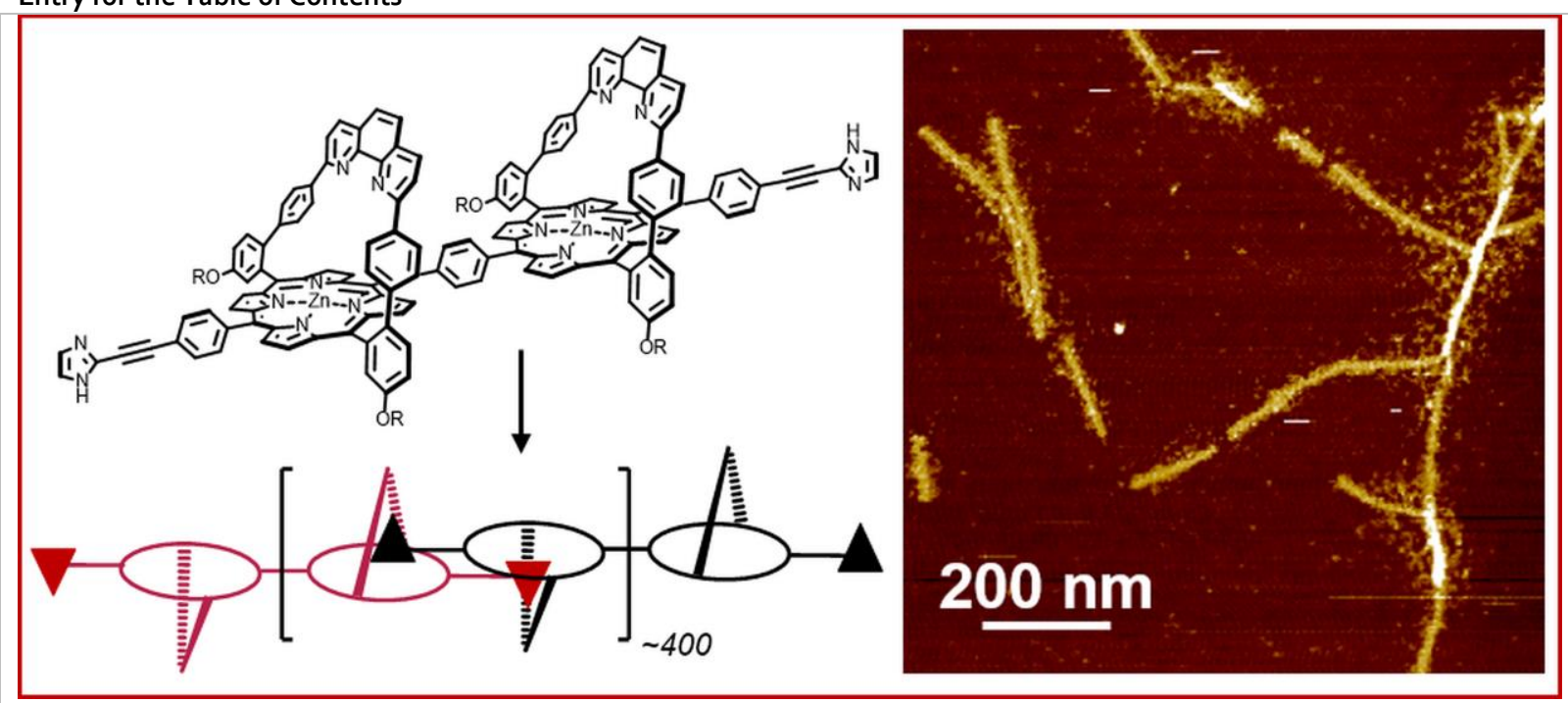

\section{Twitter}

Self-assembled growth of bis(zinc porphyrins) into micrometer-long rods required that molecules be mobile at the solvent-surface interface over a sufficiently long period. 